\title{
Cartografias participativas e abordagens em saúde e ambiente
}

\author{
Participatory mapping and approaches in health \\ and environment \\ Heloise Canal ${ }^{a}$ \\ Marla Fernanda Kuhn ${ }^{b}$ \\ ${ }^{a}$ Mestra em Geografia, Universidade Federal do Rio Grande do Sul, Porto Alegre, RS, Brasil. \\ End.Eletrônico: heloisecanal@gmail.com \\ ${ }^{b}$ Mestra em Geografia, Universidade do Vale do Rio dos Sinos, Coordenadoria-Geral de Vigilância em Saúde \\ de Porto Alegre, Porto Alegre, RS, Brasil. \\ End.Eletrônico:mfkuhn@unisinos.br
}

doi:10.18472/SustDeb.v9n1.2018.26954

Recebido em 31.08.2017

Aceito em 07.02.2018

ARTIGO-DOSSIÊ

\section{RESUMO}

Este trabalho objetiva apresentar o processo de elaboração de um mapa sobre o ambiente e sua relação com a saúde, a partir de vivências e inter-relações de trabalhadores de serviços de saúde de Porto Alegre, RS. Tal proposição surgiu da necessidade de viabilizar alternativas metodológicas de aproximação das atividades de vigilância em saúde com a Atenção Básica, trabalho compartilhado e em rede, bem como de viabilizar leituras e vivências de interação entre saúde e ambiente presentes nos territórios. O percurso metodológico seguiu a abordagem participativa da pesquisa-ação centrada no estabelecimento de diálogos de saberes e fazeres. O trabalho serviu como ponto de partida para a avaliação e o monitoramento de situações específicas de interesse à saúde ambiental. Contudo, sua maior contribuição ocorreu pela potencialidade de estabelecer parcerias de ações no campo da saúde e de suas transversalidades locais. Mais que um resultado ou uma síntese de dados, esta proposta de mapeamento constituiu-se como um dispositivo de valorização e fortalecimento das identidades territoriais, de visibilidade de conflitos ambientais, de caráter de informação e mobilização, e de articulação com dados oficiais.

Palavras-chave: Saúde Ambiental; Cartografia; Atenção Básica; Mapa Participativo; Porto Alegre.

\section{ABSTRACT}

This study aimed to present a map about the environment and its relationship with health, based on the experiences and interrelations of health service workers in the city of Porto Alegre / Brazil. This proposal presents methodological alternatives for the approximation of health surveillance activities with primary health care. The participative approach of action-research was conceived as the main strategy for this study. The work served as a starting point for the evaluation and monitoring of specific 
situations about environmental health. Besides that, the mapping approach has the potential to establish partnerships for action in the field of health in local territorial context.

Keywords: Environmental Health; Cartography; Primary Health Care; Participatory Mapping; Porto Alegre.

\section{CONTEXTUALIZAÇÃO DA CARTOGRAFIA NA TEMÁTICA DA RELAÇÃO SAÚDE E AMBIENTE}

A recente difusão de novas tecnologias de informação espacial, em especial os Sistemas de Informações Geográficas (SIG), tem reafirmado a utilização de representações cartográficas como instrumentos de conhecimento e de ação na área da saúde e sua relação com o ambiente. No entanto, essa permanência como ferramenta de conhecimento não esteve imune aos diversos movimentos de reestruturação do seu objeto e método, inclusive com relação aos estudos na temática da saúde. Lévy (2002) destaca quatro tipos de influências que são responsáveis pelas mudanças na linguagem cartográfica: o referente, ou seja, os espaços que se busca representar; os conceitos que contribuem para pensar esses espaços; as técnicas específicas e os usos do mapa dados pela sociedade. Por outro lado, ao analisar as representações cartográficas inseridas nos estudos de saúde, também devemos dimensionar a influência do próprio conceito de saúde no pensamento científico em geral.

Assim, a concepção e utilização dos mapas pela geografia e demais campos de estudo na saúde não estão restritas à distribuição espacial dos elementos e ao estudo das técnicas de representação. Também estão relacionadas ao entendimento de espaço em cada época e em cada campo do conhecimento. Antes das divisões da ciência moderna, a estruturação do conhecimento médico e geográfico instigava a busca ampliada sobre os aspectos físicos e humanos de determinada localidade nas chamadas Topografias Médicas como um dos principais e primeiros documentos que marcam esse encontro (JORI, 2013). Dessa forma, os mapas serviam como ferramentas de descrição da realidade a partir do agrupamento de fenômenos naturais e humanos, ao mesmo tempo que se buscava as relações entre fatores do meio físico, a exemplo dos fatores climáticos e a distribuição de determinadas doenças.

Diferentemente desse tipo de representação cartográfica descritiva, o médico inglês John Snow, no artigo The Mode of Communication of Cholera, publicado em 1854, evidencia o mapa como recurso analítico ao espacializar e relacionar a distribuição de pontos de captação de água e de residência com pessoas afetadas por cólera. Além de servir atualmente como marco à geografia e à epidemiologia no que se refere à análise espacial dos fenômenos, o estudo destaca-se para o campo da representação cartográfica pela escala local e urbana de análise, visto que a escala de análise predominante à época era regional.

Bousquat e Cohn (2004) ressaltam que, entre o século XIX e boa parte do XX, a aproximação dos estudos de saúde ao conceito de espaço ocorreu de forma restrita e imediata ao meio físico, por vezes sendo concebido apenas como local de interação entre os indivíduos e seus agentes patogênicos. Rojas et al. (1999) apontam que as primeiras ferramentas dos Sistemas de Informações Geográficas na área da saúde datam da década de 1950, principalmente nas análises epidemiológicas e sua relação com as condições ambientais.

A valorização do processo social na explicação do processo saúde e doença empreendida desde a década de 1970 possibilitou maior amplitude de temáticas relacionadas à Saúde Coletiva (TAMBELINNI; CÂMARA, 1998). Ao mesmo tempo, o conceito de espaço geográfico como uma realidade social (SANTOS, 2006) tornou-se um potencializador de uma nova aproximação entre a dimensão espacial e os estudos em saúde, sendo inclusive considerado um marco referencial para epidemiologistas e sanitaristas (NAJAR; MARQUES, 1998).

Atualmente, é muito difundida a utilização dos Sistemas de Informações Geográficas (SIG) nos estudos e práticas institucionais que mobilizam a relação saúde e ambiente. Destaca-se o uso nas abordagens mais centradas na avaliação da exposição (ecologia de vetores, avaliações ambientais e avaliações 
toxicológicas humanas e ambientais) e na epidemiologia (estudos em que são aplicados inquéritos em um grupo populacional definido em função do problema, os desenhos tipo caso-controle e os estudos descritivos utilizando bases de dados). Santos e Barcellos (2006) apontam as principais aplicações da análise espacial em saúde através do SIG no qual os mapas são ferramentas, como o mapeamento de doenças (construção de mapas de indicadores epidemiológicos), o relacionamento de camadas de dados sobre ambiente e saúde, a identificação de áreas de maior incidência, a avaliação e a evolução da distribuição espacial de doenças no tempo, e a análise das redes de atenção.

A capacidade de reunir e integrar dados de diversas fontes bem como a possibilidade de visualização destes em uma única interface gráfica permitiram análises mais complexas na temática da saúde. As variadas formas de apresentação das informações possibilitadas pelo SIG (tabelas, gráficos, mapas e relatórios) e a grande disponibilidade de funções de processamento de dados tornaram o mapa apenas uma das alternativas de saída gráfica do programa computacional, ou seja, uma forma de apresentação gráfica das análises e cruzamentos realizados.

Santos e Barcellos (2006) destacam as ferramentas de mapeamento em softwares como Tabwin (Datasus), o desenvolvimento de uma plataforma no ambiente Terraview (Inpe) para análises de dados espaciais em saúde, o material instrucional "Sistemas de Informação Geográfica e a Gestão da Saúde no Município" e os livros "Conceitos Básicos de Sistemas de Informação Geográfica e Cartografia Aplicados à Saúde" e "Sistemas de Informação Geográfica - Conceitos Básicos" como exemplos de iniciativas de incorporação da dimensão espacial nas análises em saúde.

Destaca-se, também, a série de livros didáticos "Capacitação em Geoprocessamento para a Saúde" elaborada pela Secretaria de Vigilância em Saúde em parceria com o CICT/Fiocruz. Assim, diante do maior acesso às tecnologias e a disponibilidade de dados e capacitação de técnicos, há uma forte incorporação de sistemas de processamento de dados espaciais pelos serviços de saúde no país, como Secretarias Municipais de Saúde e órgãos do Sistema Único de Saúde (SUS).

\section{OS MAPAS MAIS PRÓXIMOS AOS SUJEITOS E CONTEXTOS LOCAIS}

Ao analisar a utilização de mapas em estudos epidemiológicos, Rojas et al. (1999) constataram que em muitos trabalhos não há uma intencionalidade de construção de uma base teórica e metodológica do espaço, sendo este entendido ora como plano geométrico para a disposição e análise estatística de dados, ora como plano fragmentado de associação entre indicadores epidemiológicos e socioambientais, incorporando técnicas do estudo ecológico. Bueno e Lopes (2014) refletem sobre a necessidade de ampliação e readequação de ferramentas analíticas na utilização de noções de espaço e território em estudos espaciais na área da saúde.

Nesse contexto, considera-se que a busca pela análise somente pelo cálculo e pelo tratamento da informação pela lógica das ciências naturais e engenharias é limitada, já que não são consideradas as diferentes e conflituosas noções de sociedade e as inúmeras estratégias políticas de distintos atores sociais para a resolução dos problemas (FREITAS, 2003). Para além da coleta, organização e análise de grandes volumes de dados e indicadores quantitativos sobre as situações de saúde, são necessárias vias diversificadas de concretização da concepção positiva de saúde, caracterizada pelas ideias de promoção, criação de ambientes saudáveis e reforço da participação social (CZERESNIA; FREITAS, 2009). Daí a importância de serem incorporadas às análises e práticas em saúde determinadas abordagens que retomem e estruturem as formas de conhecimento centradas em estudos de casos, no resgate em experiências e histórias de vida e na ação em parceria com diferentes atores sociais.

Não seria o caso de negar as formas de explicar e de estudar o mundo sob a ótica espacial por meio das abordagens quantitativas e epidemiológicas mais tradicionais. Tem sido de grande importância, por exemplo, a elaboração e divulgação de mapas de incidências sobre doenças infecciosas por muitos municípios e instituições de pesquisa do país, principalmente após as recentes epidemias de dengue, febre amarela, chikungunya e zika. Contudo, é necessário reconhecer as limitações dessas abordagens diante da sua tendência de naturalizar a ação social, construir verdades e visões universalizantes sobre as noções de ambiente e saúde, e centralizar no campo técnico-científico as 
respostas às necessidades e aos problemas emergidos (CANAL, 2015; FREITAS, 2003; CZERESNIA; FREITAS, 2009; BUENO; LOPES, 2014).

Quando os mapas são utilizados em abordagens mais qualitativas, novos olhares podem surgir na temática da relação saúde e ambiente. Além de abarcar descrições dos elementos físico-naturais e socioculturais, os mapas focados no caráter participativo, narrativo e subjetivo das proposições cartográficas podem servir como mecanismos de valorização e fortalecimento das identidades territoriais, de visibilidade de conflitos ambientais, de caráter de informação e mobilização, e de articulação com dados oficiais.

Se o espaço geográfico, como contingência histórica do processo de reprodução social (SANTOS, 2006), é também fluidez e subjetividade, os mapas podem incorporar parte dessa complexidade se forem considerados não só seus respectivos objetivos, como também todo o processo de representação de quem os elabora e de quem os lê. A vivência e a percepção são dimensões essenciais e complementares, como fenômenos que consolidam os aspectos subjetivos associados a esse espaço (KOZEL, 2007; MONKEY et al., 2008).

Uma das distinções entre a cartografia participativa e a cartografia tradicional está relacionada ao processo de construção e uso de técnicas para a elaboração dos mapas. Enquanto a cartografia tradicional coloca como importante e, por vezes, como prioridade a precisão geométrica e tolerâncias permitidas pela escala, a cartografia participativa considera que o saber espacial dos sujeitos é mais importante que o saber cartográfico puramente técnico. Assim, o mapa passa a ser considerado como um discurso e uma forma de ver a realidade em que o "narrador" é o detentor de poder do que se revela e do que se oculta.

Santos (2011) ressalta que, embora a cartografia seja tradicionalmente denominada como uma "prática neutra", ela está inserida dentro de disputas e relações de poder, onde o que está em jogo pode ser o controle do território, de propriedade, de comportamentos e relações sociais, de processos políticos ou, das próprias formas e instrumentos de representação. Nesse contexto de disputas, é cada vez mais crescente a politização do mapa enquanto instrumento de luta social. $\mathrm{O}$ autor ressalta o crescente número de experiências de cartografias vinculadas aos movimentos sociais como instrumento de lutas de grupos socialmente desfavorecidos, o que demonstra certas transformações no próprio objeto e processo cartográfico.

Para Herliny; Knapp (2003) apud Acselard (2008, p.15), "o mapeamento participativo é aquele que reconhece o conhecimento espacial e o ambiental de populações locais e os insere em modelos mais convencionais de conhecimento". Já Goldstein et al. (2013) entendem que o mapeamento de forma participativa está relacionado a qualquer forma de registro de dados espaciais, não necessariamente segundo as convenções cartográficas.

Fida (2009, p.4) cita como "criação de mapas por comunidades locais, muitas vezes com a participação de organizações que lhes prestam apoio, entre elas autoridades públicas, ONGs, universidades e outros agentes que se dedicam ao desenvolvimento e planejamento". Independentemente do conceito desse tipo de mapeamento, há um consenso entre os autores de que os mapas elaborados a partir dessa abordagem devem valorizar o conhecimento espacial dos moradores e trabalhadores sobre as diversas dinâmicas locais. Além disso, os seus usos devem estar associados a um sentido de expressão e ação desses grupos sociais (RIBEIRO et al., 2011).

Assim, o caráter holístico ou de totalidade da relação saúde e ambiente em trabalhos interdisciplinares demanda, também, enfoques mais relativistas, contextualizados e críticos, voltados ao aprofundamento da compreensão dos processos históricos, práticas sociais e experiências humanas ante os problemas ambientais e de saúde vivenciados (SALES, 2004). Os mapas passam a ressaltar sua potencialidade para identificar a representação dos grupos sociais sobre o espaço e a produção da saúde, da doença e da cura no lugar onde vivem. Um entendimento que, muitas vezes, é incompatível à formalização geométrica em que se baseia a construção da maioria dos mapas. 


\section{RELATO DE EXPERIÊNCIA NO MUNICÍPIO DE PORTO ALEGRE, RS}

A partir dessa potencialidade de elaboração dos mapas para a compreensão das situações de saúde em uma linguagem mais simbólica, voltada às subjetividades dos sujeitos e suas práticas cotidianas expressas no espaço, este tópico objetiva apresentar o processo de elaboração de um mapa sobre o ambiente e sua relação com a saúde das pessoas, a partir de vivências e inter-relações no cotidiano do trabalho nos territórios. $O$ trabalho foi construído em parceria entre trabalhadores de serviços de saúde de Porto Alegre e pesquisadores do Programa de Pós-Graduação em Geografia da Universidade Federal do Rio Grande do Sul (Posgea/UFRGS). Tal proposição surgiu da necessidade de viabilizar alternativas metodológicas de aproximação das atividades de vigilância em saúde com a Atenção Básica, trabalho compartilhado e em rede, bem como de viabilizar leituras e vivências de interação entre saúde e ambiente presentes nos territórios.

Ao estar em permanente contato com as famílias usuárias dos serviços de saúde e no cotidiano da população no território - seja pela orientação quanto à utilização dos serviços disponíveis, pelo desenvolvimento de ações de reflexão crítica sobre processos de produção e reprodução da vida cotidiana, pelo acompanhamento às pessoas com problemas de saúde, inclusive por meio de visitas domiciliares, seja pelo cadastramento e atualização de todas as pessoas adscritas a suas microáreas -, tanto quanto dos moradores do lugar, os agentes comunitários de saúde tornam-se importantes sujeitos para o reconhecimento e produção de significados das situações e dos processos locais relacionados à saúde, ao ambiente e às condições do trabalho. Falar de reconhecimento é dar luz e força à potência das redes como dispositivo de construção coletiva dos processos pedagógicos locais.

No período de realização do estudo, a Equipe de Saúde da Família (ESF) do território em questão possuía oito trabalhadoras lotadas na função de Agentes Comunitárias de Saúde (ACS). Uma das principais atividades realizadas em parceria com elas nesta pesquisa foi a elaboração de um mapa sobre os elementos e processos da relação saúde e ambiente, a partir das suas visões e experiências sobre a área de atuação da ESF e, mais especificamente, de suas microáreas. O percurso metodológico seguiu a abordagem participativa da pesquisa-ação (THIOLLENT, 2011) centrada no estabelecimento de diálogos de saberes e fazeres. A atividade foi dividida em três etapas: mobilização, espacialização e apresentação/discussão sobre o processo de construção. ${ }^{1}$

Após a apresentação de todos os participantes, bem como a discussão sobre a proposta de trabalho, buscamos discutir com as ACS sobre a utilização de mapas no processo de trabalho da ESF bem como os usos a que lhe são destinados. As ACS utilizam do recurso de mapas, basicamente, para a atividade de territorialização das respectivas microáreas de atuação de cada ACS. Por meio da sobreposição de pontos de referência, de ruas e de moradias, são determinados os limites de cada microárea.

Os mapas são elaborados de forma analógica e sem uma preocupação com precisão geométrica (escala, projeção, etc.), já que o seu maior objetivo não é a orientação e mensuração das localizações. De certo modo, após a territorialização, o mapa em papel acaba perdendo sua visibilidade no cotidiano de trabalho considerando que a orientação por esse espaço de atuação é mentalmente projetada pelas vivências enquanto trabalhadoras e moradoras da área.

A partir dessa discussão, realizamos uma mobilização para a atividade específica de cartografia sobre a relação saúde e ambiente. Para tanto, uma linha do tempo foi desenhada abaixo de uma base cartográfica impressa de ruas do bairro com o ano de 1996 como marco de referência (ano de implementação da ESF). Cada ACS marcou na linha do tempo o ano em que se tornou moradora do bairro e o ano em que se tornou ACS. No mapa de ruas, foi marcada a localização da unidade de saúde, bem como o local de moradia de cada uma.

Essa atividade inicial objetivou sensibilizar as ACS sobre o fato de que da mesma forma que a história de vida de uma pessoa ou lugar se concretiza no tempo, essa história, conjuntamente, se concretiza no espaço. Também, teve o objetivo de tornar mais evidente que a história de vida delas se confunde com a história de ocupação e construção do bairro enquanto seu espaço de vivência do cotidiano. Observou-se que todas as oito agentes atuantes na unidade de saúde são moradoras do bairro, sendo relatado por algumas que esse fato gera certos constrangimentos, seja em relação a possíveis ameaças, 
se houver algum tipo de denúncia, seja pela abordagem que a população faz sobre os serviços de saúde em horários distintos da carga horária de trabalho. Apesar disso, todas trazem nas suas falas a relação de afeto que têm pelo bairro, principalmente pelo tempo de residência e pela dimensão físiconatural do ambiente que o faz ser distinto de uma face da cidade marcada pela intensa urbanização.

Após essa etapa, solicitamos às ACS que fizessem um relato sobre a(s) história(s) de ocupação e construção do bairro, a implantação no bairro do serviço de Atenção Básica à saúde, representado pela Estratégia de Saúde da Família, a ocorrência de eventos ambientais adversos, a formação das principais associações comunitárias, bem como a situação de saúde e doença da população. O início da ocupação residencial ocorreu a partir das casas de alto padrão, existentes na face sul do morro localizado no bairro, destinadas basicamente a épocas de veraneio ou lazer de fim de semana de famílias residentes das zonas mais centrais da cidade. Nessa área de morro, também existiu atividades de extração representadas por duas antigas pedreiras de granito.

As demais áreas urbanizadas do bairro começaram a ser ocupadas a partir da década de 1980 ao longo das estradas, constituindo pequenos núcleos urbanos. A ocupação dessa parte do bairro ocorreu via loteamentos irregulares nas áreas planas, anteriormente destinadas à pecuária e à cultura de arroz e que foram aos poucos sendo aterradas para a construção das moradias. $\mathrm{O}$ bairro ainda apresenta algumas propriedades para produção de leite e preparação de alimentos. Embora o setor comercial e de serviços do bairro seja relativamente pequeno, a população não precisa se deslocar com tanta frequência a outros bairros do entorno para adquirir itens de maior e imediata necessidade. Com relação à dinâmica de ocupação recente, as ACS apontaram a expansão nos bairros do entorno, tanto de condomínios de luxo quanto de ocupações informais. Para elas, comparativamente, o bairro não cresce tão expressivamente quanto os bairros do entorno.

Muitas das conquistas de serviços públicos no bairro foram realizadas via mobilização dos moradores nas Assembleias do Orçamento Participativo². Apesar de atuantes nas décadas anteriores, as ACS relataram que, atualmente, não há uma associação de moradores que centralize as demandas do bairro com um todo. A falta de união e de mobilização coletiva faz com que as lutas e reivindicações sejam individualizadas no que se refere à demanda de infraestrutura urbana. Essa desmobilização e a queda no grau de participação da comunidade trariam dificuldades aos trabalhadores de saúde para criação e afirmação de vínculo ${ }^{3}$, para o fortalecimento de um conselho local de saúde, bem como para o alcance efetivo e ampliado de ações individuais e coletivas de promoção da saúde e bem viver no território.

A associação de moradores mais atuante parece não abranger o bairro como um todo (seja por abrangência geográfica, seja por perfil socioeconômico). As ACS relataram que ela atua na parte oeste do bairro, abrangendo interesses dos moradores de maior poder aquisitivo. Com relação à existência de moradores residentes em áreas de risco de inundação, já que é uma área bem plana e próxima a corpos-d'água, as ACS apontaram uma área ocupada a partir de 1998 e que no período entre 2010 e 2011 houve a remoção das famílias.

Quanto à localização da unidade de saúde, verifica-se no próprio mapa (Figura 1) que ela está muito distante de quem demanda a maior parte dos serviços da unidade. Ao mesmo tempo em que alguns usuários têm dificuldade de acesso à unidade de saúde em função da distância de suas moradias, as ACS também enfrentam esse problema ao realizar as visitas domiciliares. Ademais da distância, as ACS salientaram que a estrutura física da unidade de saúde não possui capacidade para atender a todas as atividades previstas para uma ESF. Com relação à situação de saúde da população, foram destacados alguns tipos de agravos, a destacar as doenças respiratórias (asma, bronquite e infecção respiratória) e a hipertensão. Também foram citados "problemas ósseos", depressão e câncer de mama.

Embora as principais doenças relatadas tenham agravantes de maior visibilidade no âmbito individual (estilo de vida, faixa etária...), foi possível identificar que, na atividade de mapeamento dos elementos e das situações do ambiente, o grupo de ACS prioriza no seu discurso diversos problemas relacionados ao ambiente que são reconhecidos por elas como riscos à saúde. Os problemas com relação à drenagem, pavimentação, à disposição do lixo e ao acesso à praia do Lago Guaíba estão entre os mais destacados. 
A preocupação com a falta de pavimentação foi mencionada como um problema que atinge grande parte da população. Em dias mais secos, a poeira levantada pelos carros "invade" as casas, o que pode agravar o quadro de doenças respiratórias de algumas crianças e idosos. Em dias de chuva, há problemas de alagamento das ruas e, por vezes, das próprias casas. Parte das ruas não possui rede de drenagem, o que agrava os problemas relacionados aos alagamentos das vias. Outra parte significativa do bairro possui valas de drenagem que, em dias de grande precipitação, não suportam o volume de água. Os alagamentos são preocupantes, visto que carregam parte das águas residuais dos esgotos para os pátios das casas ou mesmo para o interior delas. Ademais, o grupo de ACS relatou a proliferação de mosquitos que esse tipo de drenagem acarreta às moradias. Para as ACS, houve um expressivo aumento e intensificação dos eventos de alagamentos nos últimos anos.

Com relação ao esgotamento sanitário, a maioria das moradias utiliza do sistema de fossas, visto que não há ligação à rede geral de esgoto, existindo também algumas moradias que apresentam esgoto a céu aberto. A estrutura de rede coletora já estava sendo construída por meio do Programa Integrado Socioambiental (Pisa) no momento da atividade. A previsão é de que boa parte das moradias seja ligada à Estação de Tratamento de Esgoto próxima. A proximidade dessa ETE ao bairro também foi apontada como preocupação em função do possível odor resultante do tratamento de esgoto.

As ACS evidenciaram as potencialidades ambientais favoráveis à saúde, em contraposição ao entendimento do que é o ambiente "urbano" do restante da cidade, que é marcado pela percepção de intensa poluição do ar, das águas e do solo. São características naturais e rurais, ainda preservadas, que trazem a sensação de "contato com a natureza", de "tranquilidade" e de boa qualidade ambiental. A qualidade do ar foi destacada como um condicionante positivo para a saúde da população, embora elas percebam que antes a qualidade do ar era melhor. Ainda, com relação aos elementos, valores e práticas ambientais reconhecidos como positivos à saúde da população, foi relatada por uma das ACS a prática dos moradores de utilização de plantas no tratamento e na recuperação da saúde.

Foram identificados no mapa muitos recursos de lazer, como sedes recreativas e uma extensa faixa de praia do Lago Guaíba. As sedes recreativas são propriedades particulares voltadas à confraternização e práticas de atividades de esporte e de lazer de associações específicas. $\mathrm{O}$ acesso a essas sedes é restrito aos associados, ao mesmo tempo em que há um grande déficit de espaços públicos de lazer, principalmente de praças.

Grande parte dos acessos existentes ao Lago Guaíba está em propriedade privada ou bloqueada, demonstrando que, apesar da grande extensão de orla do lago pertencente ao bairro, o acesso é restringido à maioria dos moradores. São ruas e servidões com restrição de entrada, já que os próprios moradores do entorno construíram portões de acesso. Nesse contexto de restrição ao acesso à praia e aos demais recursos de lazer, a equipe de ACS ressaltou os conflitos territoriais de dois grupos classificados como "de lá e de cá". Os moradores "de lá" vivem em uma área de morro, ao longo da orla do Lago Guaíba, e possuem um maior poder aquisitivo do que os "de cá", que vivem na parte leste do bairro, nos loteamentos irregulares.

Embora todos os moradores do bairro e do seu entorno convivam com diversas amenidades ambientais da orla do Lago Guaíba e das áreas verdes, sobretudo por estarem geograficamente em uma área de influência de condições climáticas reconhecidas como favoráveis à saúde (boa qualidade do ar e temperatura amena), muitas das potencialidades reconhecidas pelos participantes da pesquisa não estão integradas a uma concepção mais ampla de promoção da saúde coletiva. Isso porque a extensa orla de praia, as áreas verdes preservadas e demais áreas naturais do bairro, que podem ser utilizadas para o lazer e que são reconhecidas pelas ACS e pelos moradores do bairro como importantes para a saúde, não estão acessíveis à maior parte da população. São ruas e servidões com restrição de entrada à praia, onde os próprios moradores do entorno construíram portões de acesso.

Os discursos relacionados a quem está "apto ou não a utilizar a praia", por parte de determinado grupo social do bairro, demonstram que as atitudes, as experiências e os valores com relação ao ambiente se distinguem entre os moradores, por vezes gerando conflitos de uso. 
Mapa Ambiental da Unidade de Saúde da Família Ponta Grossa, município de Porto Alegre

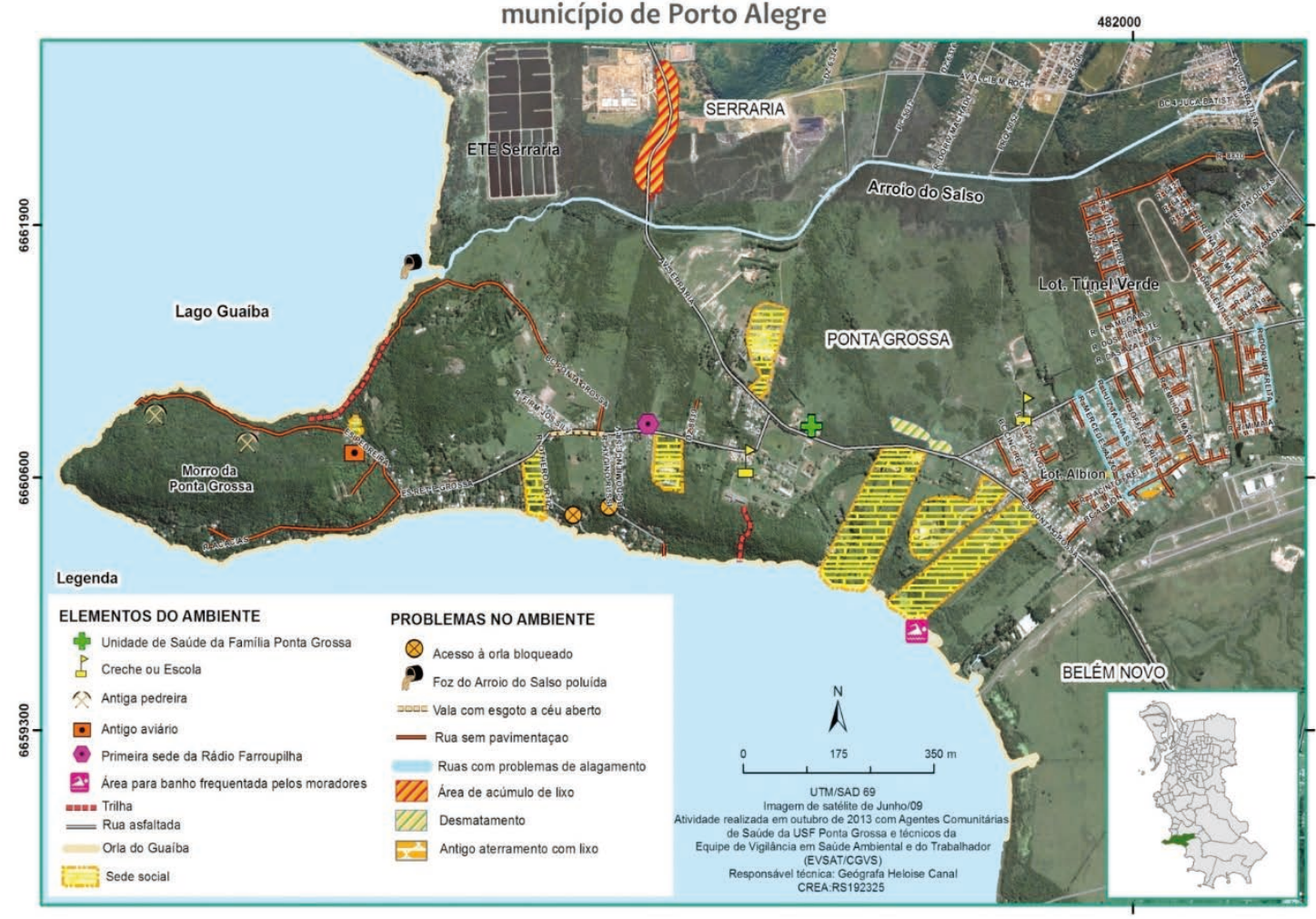

Figura 1 - Mapa sobre a dinâmica do ambiente de área de atuação de unidade de saúde em Porto Alegre/RS.

Fonte: Canal, 2015.

\section{Legenda}

\section{ELEMENTOS DO AMBIENTE}

Unidade de Saúde da Família Ponta Grossa

Ð Creche ou Escola

入 Antiga pedreira

- Antigo aviário

- Primeira sede da Rádio Farroupilha

An Área para banho frequentada pelos moradores

믐 Trilha

= Rua asfaltada

Orla do Guaíba

Sede social

\section{PROBLEMAS NO AMBIENTE}

Acesso à orla bloqueado

Poz do Arroio do Salso poluída

בपCᄃ Vala com esgoto a céu aberto

Rua sem pavimentação

Ruas com problemas de alagamento

1 Área de acúmulo de lixo

1 Desmatamento

$\mathrm{x}^{3}$ Antigo aterramento com lixo

Figura 1 - Mapa sobre a dinâmica do ambiente de área de atuação de unidade de saúde em Porto Alegre/RS.

Figura 2 - Legenda do Mapa.

Fonte: Canal, 2015. 


\section{PARA ALÉM DA SÍNTESE: O MAPA COMO PROCESSO DE NARRATIVA E DE CONSTRUÇÃO DE PARCERIAS}

ADo diálogo com trabalhadores em saúde surgiram questionamentos sobre o "uso" mais convencional da cartografia, o que colocou em evidência uma série de desafios e, principalmente, possibilidades de se pensar a linguagem espacial representadas nos mapas. Do uso do mapa como instrumento de análise sobre riscos à exposição de indivíduos, passou-se a incorporar o uso do mapa com/para a participação dos sujeitos. A partir do reconhecimento da cartografia participativa sobre os saberes espaciais, históricos e ambientais das ACS, novos usos e possibilidades foram destacados, já que a representação cartográfica foi evidenciada enquanto narrativa das respectivas vivências e percepções. Nessa concepção, o mapa passou a ser evidenciado como uma leitura que é construída e percebida por diferentes sujeitos.

A proposta de leitura sobre a relação saúde e ambiente na área de atuação da ESF permitiu uma avaliação preliminar de riscos e condições favoráveis à saúde da população adscrita a esse território. Ela serviu como ponto de partida para a avaliação e o monitoramento de situações específicas de interesse à saúde ambiental. Constatou-se a presença de situações que podem gerar problemas de saúde relacionados à precariedade dos serviços urbanos, como falta de saneamento e de pavimentação adequada em pontos específicos do bairro, o que pode intensificar casos de doenças infecciosas e doenças respiratórias.

O fato de o bairro ainda preservar características e processos produtivos rurais, como produção de leite, ao mesmo tempo em que possui atividades de comércio e pequena indústria de materiais odontológicos, torna mais complexa a atuação da vigilância em saúde do município no que diz respeito à fiscalização sanitária e ambiental de locais que apresentam potencial de poluição e contaminação. Além dos processos produtivos de interesse à temática, o processo de construção do mapa colocou em destaque alguns conflitos territoriais, embasados principalmente nos discursos de mobilização por moradia, preservação ambiental e acesso às áreas públicas de orla.

Isso demonstra a importância de pensar a relação saúde e ambiente, não só aos problemas mais imediatos relacionados à precariedade sanitária, como também pensar os impactos decorrentes dos processos produtivos e de (re)organização do espaço urbano. A própria dinâmica de expansão nos bairros do entorno de condomínios residenciais de luxo e de ocupações informais aponta para uma possível expansão das desigualdades sociais e territoriais no bairro, tendendo a um aumento do grau de complexidade e de iniquidade da situação de saúde das populações.

Se nas décadas anteriores a valorização das áreas urbanas do município ocorria, predominantemente, nas zonas mais centrais, em função da localização em relação aos postos de trabalho e ao acesso aos principais serviços urbanos (FURTADO, 2011), o processo de leitura com os participantes da pesquisa possibilitou observar que, atualmente, a cidade convive com outro fenômeno de valorização das áreas urbanas, centrado na busca pelos aspectos "naturais" e de "tranquilidade" da zona sul da cidade. Assim, o "natural" é cada vez mais apropriado, ressignificado e presente no meio urbano, pela busca do "contato com a natureza".

Além de poder contribuir como meio e produto de uma análise sobre a situação de saúde e do ambiente nos territórios, podemos enaltecer a proposta de mapeamento como potencialidade de estabelecer parcerias de ações no campo da saúde e de suas transversalidades locais, como um processo de diálogo e de práticas entre os sujeitos que a construíram. Considerando o potencial de diálogo, de convergências e divergências, bem como os vários graus de participação construídos ao longo do trabalho, concluímos que, mais que um resultado ou uma síntese de dados, esta proposta de mapeamento no campo da saúde ambiental constitui-se como um dispositivo potente rumo à participação mais ativa dos sujeitos locais na busca por estratégias, afirmação de resistências, e pelas ações de fortalecimento da cultura local de cuidado e promoção da saúde ambiental.

Foi possível, também, dimensionar a relação saúde e ambiente para além do meio físico, ressaltando diversas práticas, vivências e olhares existentes nesses bairros, que podem sim ser balizadores da articulação entre população e trabalhadores da saúde. Pode-se destacar o sentido de pertencimento 
da comunidade ao território, marcado pela sua história, pelas lutas por direitos e pelas relações de afeto e de vizinhança. Este pode ser um caminho para enxergar a saúde para além das doenças e dos agravos. Nesse contexto, um dos objetivos para a construção de parcerias locais, a partir da presente proposta de leitura, pode estar centrado no potencial de visibilidade das diferentes disputas para impor determinados usos ao território, principalmente empreendimentos econômicos e produtivos. Nesse caso, as Equipes de Saúde, em articulação com outros setores públicos, comunidade e movimentos sociais, possuem um papel fundamental de promoção da saúde por meio do enfrentamento das diversas iniquidades em saúde derivadas das injustiças ambientais e territoriais.

No contexto de análise do bairro, esse enfrentamento pode ter maior visibilidade na concretização do acesso da maior parte da população às condições favoráveis à promoção da saúde e do bem viver, do que de forma mais direta nos efeitos e nas consequências ambientais negativas derivadas dos processos produtivos. É na perspectiva de reconhecimento das diversas territorialidades existentes no bairro e da valorização e acesso aos espaços reconhecidos como "saudáveis" que as potencialidades podem ser trabalhadas como promovedoras da saúde. Nesse sentido, a promoção da saúde pela promoção da justiça ambiental ultrapassa a concepção de ações em saúde centradas na "conscientização" sobre práticas sanitárias e estratégias individualizadas de relação com o ambiente. Ela é estruturada a partir da busca por "movimentos de resoluções dos problemas ambientais de forma socialmente justas, economicamente viáveis, ecologicamente prudentes e politicamente emancipadoras" (FREITAS, 2003, p. 138).

É necessário, também, ressaltar que os alcances deste trabalho e das ações propostas dependem, diretamente, do grau de participação e envolvimento das equipes de saúde. Conforme o grau de participação gerado ao longo da pesquisa, no caso da busca por uma participação de consultiva a propositiva, maior o grau de complexidade de relações coletivas e institucionais envolvidas. O nível de parceria possui maior complexidade em relação ao nível de consulta, já que os parceiros concordam e compartilham as atividades de planejamento e a tomada de decisão. Notemos, também, que as parcerias de ação estão, essencialmente, no âmbito institucional, mas também são regidas pelas instâncias individuais e coletivas.

Por fim, considerando a importância de construção de políticas públicas participativas, emancipatórias e autônomas, de ações em saúde voltadas ao território, ressaltamos a viabilidade da leitura proposta ser estabelecida e construída coletivamente com as demais Estratégias de Saúde da Família, bem como em parceria com moradores, organizações e movimentos sociais das respectivas áreas de atuação. Que outros olhares sobre a relação saúde-ambiente e processos produtivos existiriam e poderiam ser construídos nos demais territórios de Porto Alegre? É tomando como base o (re)conhecimento das complexidades e desigualdades das situações ambientais e de saúde que as ações nesse campo devem ser fortalecidas. Pela busca de métodos e processos de pesquisa e investigação abertos e complementares, acompanhando, assim, os discursos e perspectivas de ação coletiva, em rede e democrática, cada vez mais ressaltadas nas políticas de saúde coletiva vinculadas às questões ambientais.

\section{NOTES}

1 A pesquisa foi submetida e aprovada pelos Comitês de Ética das respectivas instituições participantes, cumprindo as Resoluções Éticas Brasileiras, em especial a Resolução CNS 466/2012.

2 O Orçamento Participativo (OP), existente desde 1989 no município, consiste em um processo de decisão da população diretamente sobre a definição das prioridades de investimento do orçamento público. Ao elencar as obras e serviços decididos pela população por meio do Orçamento Participativo desde 1990, observa-se que as demandas estão relacionadas à ampliação dos serviços de saúde e educação, reassentamentos de famílias residentes em áreas de risco de inundação e obras de saneamento e pavimentação. Fonte: http://www.observapoa.com.br.

${ }^{3} \mathrm{O}$ vínculo refere-se à construção de relações de afetividade e confiança entre o usuário e o trabalhador da saúde, permitindo o aprofundamento do processo de corresponsabilização pela saúde, construído ao longo do tempo, além de carregar, em si, um potencial terapêutico (PNAB, 2012). 


\section{REFERENCES}

BACSELRAD, H. (Org). Cartografias sociais e território. Rio de Janeiro: UFRJ/IPPUR, 2008.

Cartografia social e dinâmicas territoriais: marcos para o debate. Rio de Janeiro: IPPUR/UFRJ, 2010.

ASSOCIAÇÃO BRASILEIRA DE SAÚDE COLETIVA (ABRASCO). 1a Conferência Nacional de Saúde Ambiental: cadernos de textos, Grupo de Trabalho Saúde e Ambiente da Associação Brasileira de Pós-Graduação em Saúde Coletiva, 2009.

BOUSQUAT, A.; COHN, A. A dimensão espacial nos estudos sobre saúde: uma trajetória histórica. História, Ciências, Saúde - Manguinhos, vol. 11, n. 3, p. 549-68, set./dez. 2004.

BRASIL. Ministério da Saúde. Conselho Nacional de Saúde. Subsídios para construção da Política Nacional de Saúde Ambiental. Ministério da Saúde, Conselho Nacional de Saúde. Brasília: Editora do Ministério da Saúde, 2007.

BRASIL. Ministério da Saúde. Secretaria de Atenção à Saúde. Departamento de Atenção Básica. Política Nacional de Atenção Básica. Ministério da Saúde. Secretaria de Atenção à Saúde. Departamento de Atenção Básica. Brasília: Ministério da Saúde, 2012.

BUSS, P.; PELLEGRINI, A. F. A Saúde e seus determinantes sociais. Physis: Rev. Saúde Coletiva, Rio de Janeiro, v. 17 , n. 1, p. 77-93, 2007

CANAL, H.; VERDUM, R. Mapeamento ambiental integrado: município de Porto Alegre, RS, Confins [On-line], 19 | 2013, posto on-line no dia 12 Novembro 2013, consultado em 30 Abril 2015. URL: http://confins.revues. org/8583; DOI: $10.4000 /$ confins.8583

CANAL, H. Construindo e conhecendo a saúde pelo ambiente: uma proposta de leitura participativa e territorializada em Saúde Ambiental. Dissertação (Mestrado em Geografia) - Universidade Federal do Rio Grande do Sul, Instituto de Geociências, Programa de Pós-Graduação em Geografia, Porto Alegre-RS, 2015.

CATTANI, A. (Org.) et al. Vigilância em saúde de Porto Alegre: a construção de uma história. Porto Alegre: Finaliza Editora, 2011.

CZERESNIA, D.; FREITAS, C. M. Promoção da saúde: conceitos, reflexões, tendências. 2a edição rev. ampl. Rio de Janeiro: Fiocruz, 2009.

FONDO INTERNACIONAL DE DESARROLLO AGRÍCOLA (FIDA). Buenas prácticas en cartografía participativa: análisis preparado para el Fondo Internacional de Desarrollo Agrícola (FIDA), 2009.

GOLDSTEIN, R. A. et al. A experiência de mapeamento participativo para a construção de uma alternativa cartográfica para a ESF. Ciênc. e Saúde Coletiva, v. 18, n. 1, p. 45-56, 2013.

JORI, G. El estudio de la salud y la enfermedad desde una perspectiva geográfica: temas, enfoques y métodos. Biblio 3W. Revista Bibliográfica de Geografía y Ciencias Sociales. Barcelona: Universidad de Barcelona, v. XVIII, n. 1029. 2013 Disponível em: <http://www.ub.es/geocrit/b3w-1029.htm> Acesso em: abr. 2014.

HERLIHI, P. H. \& KNAPP, G. (eds.). Maps of, by and for the Peoples of Latin America. Human Organization. Journal of the Society for Applied Anthropology. Vol. 62, No. 4, 2003.

KOZEL, S. Da percepção e cognição à representação: reconstruções teóricas da geografia cultural e humanista. São Paulo: Terceira Margem, 2007.

MONKEN, M.; BARCELLOS, C. Vigilância em saúde e território utilizado: possibilidades teóricas e metodológicas. Cadernos de Saúde Pública, v. 21, n. 3, 2005. p. 898-906.

NAJAR, A.; MARQUES, E. (Org.). Saúde e espaço: estudos metodológicos e técnicas de análise. Rio de Janeiro: Editora Fiocruz, 1998.

RADICCHI, A. L. A.; LEMOS, A. F. Saúde Ambiental. Belo Horizonte: Editora Coopmed - Nescon UFMG, 2009. 
RIBEIRO, A. C.; CAMPOS, A.; SILVA, C. A. (Org.). Cartografia da ação e movimentos da sociedade: desafios das experiências urbanas. Rio de Janeiro: Lamparina, Capes, 2011.

ROJAS, L. I.; BARCELLOS, C.; PEITER, P. Utilização de mapas no campo da Epidemiologia no Brasil: reflexões sobre trabalhos apresentados no IV Congresso Brasileiro de Epidemiologia. Informe Epidemiol. SUS, Brasília, v. 8, n. 2, p. 27-35, jun. 1999.

SANTOS, M. A Natureza do Espaço: técnica e tempo, razão e emoção. 4. ed. São Paulo: Editora da Universidade de São Paulo, 2006.

SANTOS, S. M.; BARCELLOS, C. (Org.). Abordagens espaciais na Saúde Pública. Ministério da Saúde, Fundação Oswaldo Cruz. Brasília, 2006.

THIOLLENT, M. J. Metodologia da pesquisa-ação. 18. ed., São Paulo: Cortez, 2011.

TUAN, Y. Topofilia: um estudo da percepção, atitudes e valores do meio ambiente. São Paulo: Difel, 1974. 